\title{
Natural Convection Heat Transfer Around a Horizontal Circular Cylinder for the Case of Constant Surface Temperature of the Cylinder Near a Vertical Wall
}

\author{
Marcel Novomestsky ${ }^{1, *}$, Roman Banovčan ${ }^{1}$, Andrej Kapjor ${ }^{1}$, and Helena Smatanová ${ }^{1}$ \\ ${ }^{1}$ University of Žilina, Department of Power Engineering, 01026 Žilina, Slovakia
}

\begin{abstract}
Natural convection heat transfer from a single horizontal cylinder near an isothermal wall is experimentally investigated in the environmental chamber. The cylinder is heated with constant temperature, the rising plum from the heated cylinder interacts with the side wall and significantly affects the surface heat transfer distribution. Thus, the distance between horizontal cylinder and side wall can influence the heat transfer. The heat transfer from heated cylinder with different distances were compared. Results are obtained for $\mathrm{Ra}=10^{4}$. It was found that natural convection heat transfer from horizontal cylinder depends on the distance between wall. Also, a heat transfer correlation has been proposed for a single horizontal cylinder near a wall and is compared with earlier work. The results indicate that the vertical wall affect the average Nusselt number at the cylinder. Therefore, the vertical wall has a positive effect on the Nusselt number at the cylinder.
\end{abstract}

\section{Introduction}

The natural convection flow in horizontal annuli has received increased attention in last decade because of their importance in engineering. Natural convection heat transfer is an inexpensive, reliable and noise-free method of heat transfer. For instance, horizontal cylinder has many engineering applications such as heat exchangers, radiators, thermal storage systems, and cooling of electronic components.

Past decade has witnessed extensive work on convective heat transfer from cylindrical surface. Morgan [1], Churchill and Chu [2] have determined empirical correlation equations which focus mainly on Nusselt number. Kuehn and Goldstein [3] investigated natural convection around an isothermal circular cylinder for Rayleigh numbers of $<10^{7}$ and have solved the full Navier -Stokes and energy equations. Kuehn and Goldstien have shown that the heat transfer is at its maximum at the bottom of the cylinder and decreases toward the top of the cylinder. The decrease in heat transfer is attributed to an increase of the thermal boundary layer thickness.

\footnotetext{
${ }^{*}$ Corresponding author: marcel.novomestsky@,fstroj.uniza.sk
} 
Later, Fujii et al. [4] presented experimental results on natural convection heat transfer from horizontal wire. They used two computational domains, one is a domain near the cylinder and the other is one outside this domain. For order to check the validity of the boundary conditions they used an open and a solid boundary condition.

In particular, natural convection from horizontal cylinder has received considerable attention in the literature because of the fundamental nature of the geometry. The heat transfer from a cylinder near the side wall is quite different with respect to the one from a single cylinder due to the interaction of the side wall. This interaction is owing to the buoyant plume that is generated by cylinder.

The current research investigates the distribution of the heat transfer from horizontal heated cylinder near the side wall under natural convection conditions in air. This experimental study considers the influence of distance between wall and cylinder. The range of cylinder and wall spacing was taking from no inflation distance to distance closed to the wall.

In this article, we consider natural convection, alternatively called free convection, where any fluid motion occurs by natural means such as buoyancy. The buoyancy force is caused by the density difference between the heated fluid adjacent to the surface and the fluid surrounding it and is proportional to this density difference and the volume occupied by the warmer fluid.

\section{Experimental apparatus}

The experimental apparatus consists essentially of a heated circular cylinder mounted horizontally on holding construction and placed in the environmental chamber.

\subsection{Experimental cylinder and installation of thermocouples}

The experimental device is circular cylinder (1) Figure1 made of stainless steel with length of $1 \mathrm{~m}$. The air flows due to the buoyancy effect. The cylinder is heated electrically by using an electrical heater as shown in Figure 1. It consists of nickel-chrome wire (3) electrically isolated by ceramic beads and wound uniformly along the cylinder as a coil in order to give uniform heat flux. For measuring the cylinder surface temperature were used $\mathrm{NiCr}-\mathrm{Ni}$ (type K) thermocouples (2) mounted inside of the cylinder close to the surface in the middle of the cylinder. The outlet air temperature was measured by one resistance thermometer placed in the middle of the environmental chamber [6].

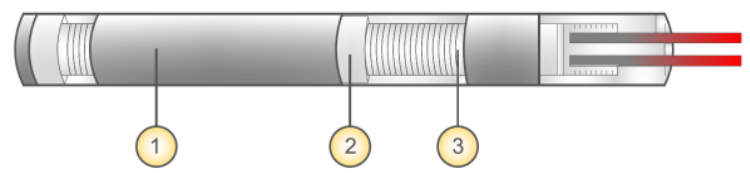

Fig. 1. Longitudinal section of experimental cylinder.

\subsection{Environmental chamber}

Experimental investigation was obtained in the environmental chamber Figure 2, where the surround temperature $\mathrm{T}_{\infty}$ was set to constant $20^{\circ} \mathrm{C}$. 


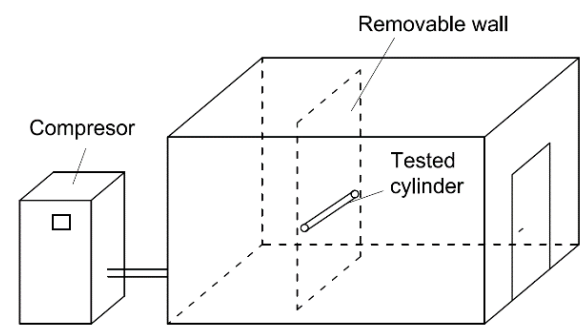

Fig. 2. An environmental chamber for performance tests.

The environmental chamber has almost constant conditions Table 1 . The relative humidity was during the test between $52-67 \%$ which has only small influence on the air density.

Table 1. Environmental chamber conditions.

\begin{tabular}{|c|c|c|}
\hline $\mathrm{T}_{\infty}\left[{ }^{\circ} \mathrm{C}\right]$ & $\mathrm{P}[\mathrm{kPa}]$ & $\mathrm{rH}[\%]$ \\
\hline $20 \pm 0.05$ & 96.8 & $52-67$ \\
\hline
\end{tabular}

Thermal output measurement is based on the norm STN EN 442: 2000. According to this norm, the test area must be equipped with:

- closed chamber without ventilation with space for installation of the test specimen and a water-cooled surface in order to achieve a certain temperature conditions independent on the external environment,

- device for cooling the water which run in the wall of the chamber,

- primary heating circuit constructed to supply test specimen,

- measuring instruments and control equipment meeting the requirements of norm [5].

\subsection{Formulation}

It was assumed that the flow is steady, and no slip condition occurs. Thermo-physical properties of the air are assumed to be constant except for the density variation, which is approximated by the Boussinesq model. The cylinder surface is maintained at a constant temperature $T_{s}$ which is higher than the outer temperature $T_{\infty}$. The side wall temperature $T_{w}$ is equal to the outer temperature $T_{\infty}$. The momentum equation, for laminar natural convection flow over cylinder may be written under the Boussinesq approximation as follows [7]:

$$
\left(\rho-\rho_{\infty}\right) g \approx-\rho_{\infty} \beta\left(T-T_{\infty}\right) g
$$

where $\rho_{\infty}$ is the (constant) density of the flow, $T_{\infty}$ is the operating temperature, and $\beta$ is the thermal expansion coefficient. Equation 1 is obtained by using the Boussinesq approximation $\rho=\rho_{\infty}(1-\beta \Delta \mathrm{T})$ to eliminate $\rho$ from the buoyancy term. This approximation is accurate as long as changes in actual density are small, specifically, the Boussinesq approximation is valid when $\beta\left(T-T_{\infty}\right)<1$. The Boussinesq module should not be used if the temperature differences in domain are large.

\subsection{Experimental procedure}

A voltage regulator (matrix), digital ammeter and digital voltmeter were used to control and measure the input power to the working cylinder (Figure 3). The apparatus was allowed to run till pseudo-steady state conditions were achieved. The reading of thermometer and 
resistance thermometer were recorded every 2 min by digital electronic device until the reading became constant, and then, after half hour, the final reading was recorded [8].

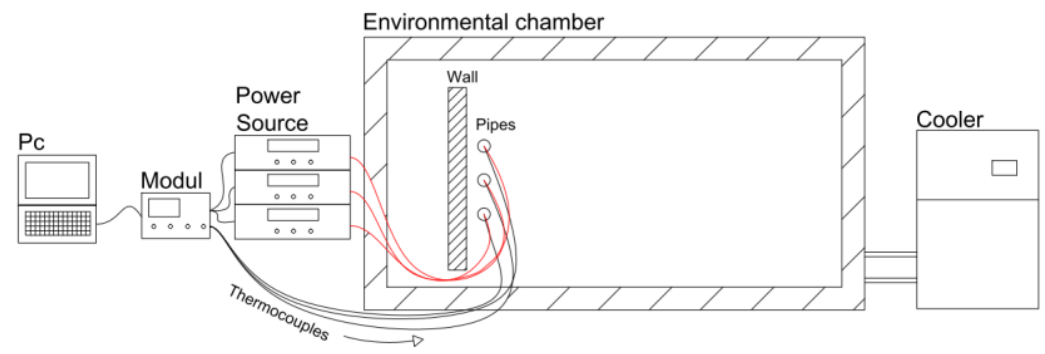

Fig. 3. Schematic of the data acquisition system.

\subsection{Data analysis method}

The confinement ratio $C$ is the first control parameter of the experiments $(C=X / r)$, where $X$ is distance between the wall and the cylinder as shown Figure 4, and $r$ is a cylinder radius). Nine different confinement ratios $C$ will be investigated in this study: $C=1.5 ; 2 ; 2.5 ; 3 ; 4$; $5 ; 8$ and 10 . The second control parameter $(\Delta T)$ is the difference between the cylinder surface temperature $\left(T_{S}\right)$ and the air bulk $\left(T_{\infty}\right)$. The air bulk temperature is measured in the middle of the environmental chamber. This second parameter dictates the natural convection flow regime and is generally expressed in the form of the Rayleigh number define as [9]:

$$
R a=\beta g D^{3} \Delta \operatorname{TPr} / v^{2}
$$

where $\beta$ is the volumetric thermal expansion coefficient of the fluid, $g$ is the gravitational constant, $\mathrm{Pr}$ is the Prandtl number and $v$ is the kinematic viscosity of air. All parameters are evaluated at the fluid temperature define as:

$$
T_{f}=\left(T_{\mathrm{s}}+T_{\infty}\right) / 2
$$

In the work reported here, the maximum Rayleigh number was of the order of $10^{4}$, meaning that the flow is nominally still laminar.

The convection heat transferred from the heated cylindrical surface can be calculated as:

$$
Q_{\text {conv. }}=Q_{I P}-Q_{\text {rad }}
$$

The total input power supplied to the heated cylinder can be calculated as

$$
Q_{I P}=V \times I
$$

The radiation heat transfer from the tube can be calculated from:

$$
Q_{\text {rad. }}=A_{s} \varepsilon \sigma\left(T_{s}^{4}-T_{\infty}{ }^{4}\right)
$$

where $A_{s}$ is the surface area of the tube $=\pi \times d \times L ; \varepsilon$ is emissivity of given material; and $\sigma$ is Stefan-Boltzmann constant $=5.66 \times 10^{-8} \mathrm{~W} / \mathrm{m}^{2} \mathrm{~K}^{4}$.

After calculating the radiative heat transfer from the cylinder, it was noticed that it is very small compared with the total heat transfer, and consequently, it can be ignored.

The convection heat transfer can be obtained from:

$$
Q_{\text {conv. }}=Q_{\text {conv. }} / A_{s}
$$


where $A_{s}=\pi \times d \times L$.

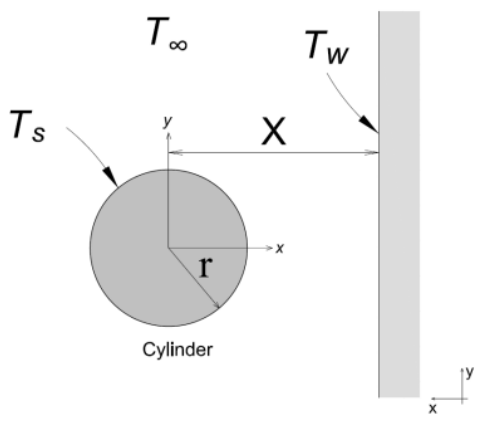

Fig. 4. Physical model and coordinates.

\section{Experimental results}

A total of 54 test runs were conducted to cover 9 different distances for heated circular cylinder with length of $1 \mathrm{~m}(L / D=5)$. The range of surface temperature was varied from $40{ }^{\circ} \mathrm{C}$ to $90{ }^{\circ} \mathrm{C}$.

\subsection{Surface temperature}

Generally, many variables such as heat flux and flow restriction situation may affect the variation of the surface temperature of the pipe. In this case, the surface temperature of the cylinder is constant for all distances. When the hot cylinder is moving closer to the wall, the temperature of the cylinder gradually decrease. This mean to maintain the constant temperature of the cylinder, the input power is increasing.

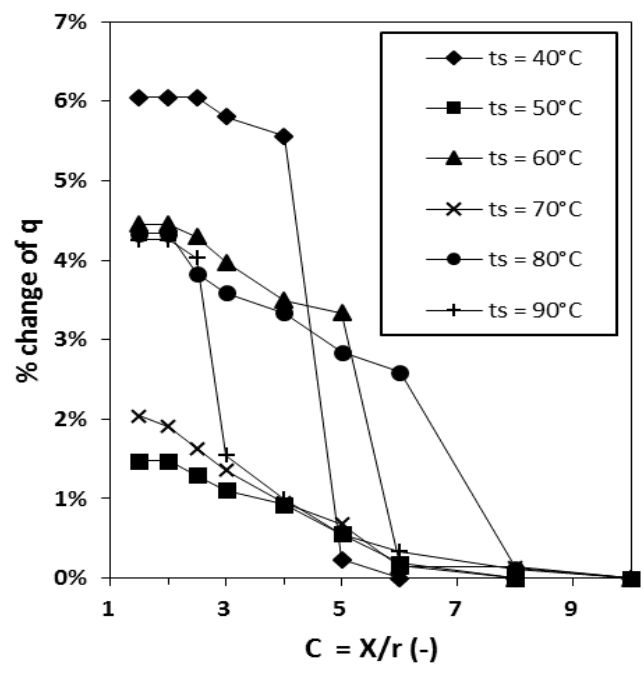

Fig. 5. Percentage change of input power with distance from the wall.

For analysis of the natural convection heat transfer around a horizontal cylinder with the constant surface temperature the temperature parameter was analysed for $10^{4}$ Rayleigh 
number. The surface temperature of the cylinder is taken with one thermocouple placed in the middle of the cylinder close to the cylinder surface.

The results how the input power is change when the cylinder is moved are shown in the Figure 5. The heat flux exhibits a larger change when the distance between the cylinder and the wall is less than $60 \mathrm{~mm}$ for all tests.

\subsection{Effect of wall confinement}

The experimental data obtained from this investigation analyses the effects of the confining wall on the rate of heat rejection from surface of the heated cylinder. For this study, the maximum average Nusselt number occurs at a confinement ratio $C=1.5$.

\subsection{Average heat transfer correlation}

The general correlation obtained by dimensional analysis from Incropera and DeWitt [10] for heat transfer by natural convection is:

$$
N u_{D}=f_{1}(G r, P r)^{n}
$$

In the case of heat transfer from cylinder to vertical wall, one expects that there is effect of distance between the wall and the cylinder. For similarity with a horizontal cylinder, the characteristic linear dimension in the $N u$ and $G r$ may be taken as the cylinder diameter $(D)$ and the effect of the distance between wall and cylinder may be taken as $C=X / r$. Then, Eq. (8) becomes:

$$
N u_{D}=f_{2}(G r, P r)^{n \cdot} C^{m}
$$

Therefore, the following correlation was obtained from the present study for smallest and biggest surface temperature and a general correlation was obtained for all distances shown in Figures $6-7$.

$$
N u_{D}=0.57(G r, P r)^{0.25} C^{-0.035}
$$

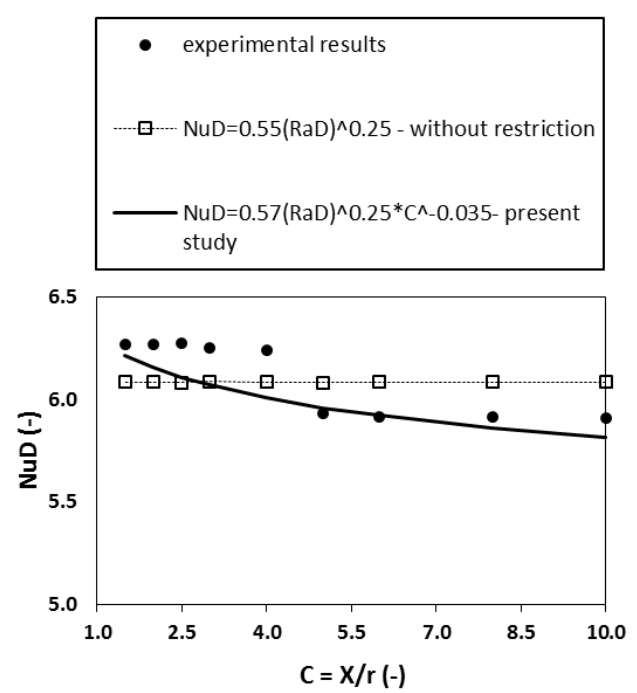

Fig. 6. Correlation between average Nusselt number versus confinement ratio for smallest $\mathrm{Ts}=40{ }^{\circ} \mathrm{C}$. 


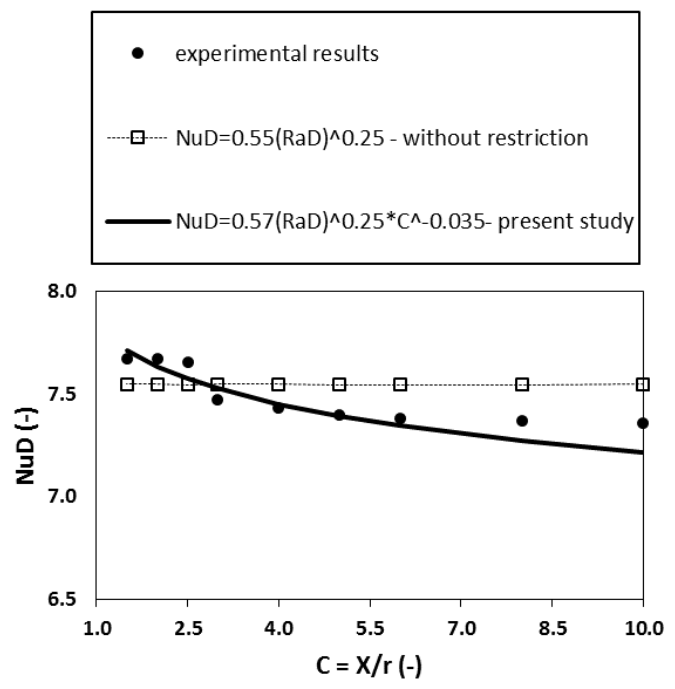

Fig. 7. Correlation between average Nusselt number versus confinement ratio for highest $\mathrm{Ts}=90{ }^{\circ} \mathrm{C}$.

As a comparison between the present study and normal case, which included a horizontal cylinder in the free air without any restrictions, the correlation obtained for the normal case from Incropera [10] is,

$$
N u_{D}=0.55(G r, P r)^{0.25}
$$

Comparing Eq. 10 with the Eq. 11 for this study shown in the Figures 6-7, is proven that the distance between the wall and the cylinder has an effect on the heat transfer results.

The difference of present correlation with Incropera work is about $5 \%$ which is not counting with wall confinement.

\section{Conclusions}

An experimental study of a laminar natural convection heat transfer from a single horizontal cylinder near an isothermal wall was conducted. Laminar convection heat transfer causes flow because the density differences. The flow moved up around the hot cylinder and continued upward when the cylinder was not interacted with the wall. The flow moved across the wall when the upward flow is interacted with colder wall and began mainly when the distance between the wall and the cylinder of $20 \mathrm{~mm}$ diameter was less than $60 \mathrm{~mm}$. The highest heat flux change occurs at confinement ratio 1.5. The improvement of correlation in this study is up to $5 \%$.

\section{Nomenclature}

$A_{s}=$ Cylinder surface area, $\left(\mathrm{m}^{2}\right)$

$C=$ Confinement ratio, $\mathrm{C}=\mathrm{X} / \mathrm{r}(-)$

$D=$ Diameter of circular cylinder, $(\mathrm{m})$

$g=$ Gravitational acceleration, $\left(\mathrm{m} / \mathrm{s}^{2}\right)$

$\mathrm{Gr}=$ Grashoff number, $(-)$

$I=$ Heater current, (A)

$k=$ Thermal conductivity, (W/m.k)

$\mathrm{Nu}=$ Average Nusselt number, (-) 
$\operatorname{Pr}=$ Prandtl number, (-)

$q=$ Heat flux, $\left(\mathrm{W} / \mathrm{m}^{2}\right)$

$Q_{\text {conv. }}=$ Convection heat transfer, $(\mathrm{W})$

$Q_{I P}=$ Total input power, $(\mathrm{W})$

$Q_{\text {rad }}=$ Radiant heat transfer, $(\mathrm{W})$

$r=$ Radius of circular cylinder, $(\mathrm{m})$

$R a=$ Rayleigh number, (-)

$T=$ Temperature, $\left({ }^{\circ} \mathrm{C}\right)$

$T_{s}=$ Temperature of the surface, $\left({ }^{\circ} \mathrm{C}\right)$

$T_{W}=$ Temperature of the wall, $\left({ }^{\circ} \mathrm{C}\right)$

$T_{\infty}=$ Temperature of the cold surface, $\left({ }^{\circ} \mathrm{C}\right)$

$\Delta T=$ Temperature difference, $(-)$

$k=$ Thermal conductivity, (W/m.k)

$V=$ Heater voltage, $(\mathrm{V})$

$X=$ Distance from centre of square cylinder to wall,

$x=$ Cartesian coordinate in horizontal direction, $(\mathrm{m})$,

$y=$ Cartesian coordinate in vertical direction, (m)

\section{Greek Symbols}

$\alpha=$ Thermal diffusivity, $\left(\mathrm{m}^{2} / \mathrm{s}\right)$

$\beta=$ Volumetric coefficient of thermal expansion, $(1 / \mathrm{K})$

$\mu=$ dynamic viscosity of the fluid, (kg/m.s)

$\varepsilon=$ Emissivity, (-)

$\sigma=$ Stefan-Boltzmann constant, $\left(\mathrm{W} / \mathrm{m}^{2} \mathrm{~K}^{4}\right)$

$\rho=$ Density of the fluid, $\left(\mathrm{kg} / \mathrm{m}^{3}\right)$

$v=$ Kinematic viscosity of the fluid, $\left(\mathrm{m}^{2} / \mathrm{s}\right)$

This work was supported by Department of Power Engineering under APVV-15-0778 Limits of Radiative and Convective Cooling through the Phase Changes of Working Fluid in Loop Thermosyphon.

\section{References}

1. V.T. Morgan, Advances in Heat Transfer 11 (1975)

2. S.W. Churchill, H.H.S. Chu, Intern. Journal of Heat and Mass Transfer 18 (1975)

3. T.H. Kuehn, R.J. Goldstein, Intern. Journal of Heat and Mass Transfer 23 (1980)

4. T. Fujii, M. Fujii, T. Honda, Proc. of the 7th intern. heat transfer conference 6 (1982)

5. STN EN 442-2:2000, (1996)

6. A. Kapjor, Habilitation thesis (2012)

7. Ansys fluent, User's Guide 15 (2009)

8. R. Lenhard, J. Jandačka, M. Malcho, Vetranie a klimatizácia (2008)

9. M. Novomestský, H. Smatanova, A. Kapjor, AIP Proc. 1745 (2016)

10. F.P. Incropera, et al., Fundamentals of heat and mass transfer 7 (2011)

11. M. Čarnogurská, M. Př́íhoda, T. Brestovič, J. Molínek, R. Pyszko, Journal of Mechanical Science and Technology 26, 1 (2012) 